\title{
Climate Change and Biodiversity Threats on Pachypodium Species in South Africa
}

\author{
Danni Guo, Leslie W. Powrie, Danielle W. Boyd \\ South African National Biodiversity Institute, Kirstenbosch Research Center, Claremont, Cape Town, RSA \\ Email: d.guo@sa nbi.org.za, leslie_powrie@yahoo.co.uk, daniellewboyd@gmail.com
}

How to cite this paper: Guo, D. N., Powrie, L. W., \& Boyd, D. W. (2019). Climate Change and Biodiversity Threats on Pachypodium Species in South Africa. Journal of Geoscience and Environment Protection, 7, 37-44.

https://doi.org/10.4236/gep.2019.75004

Received: April 16, 2019

Accepted: May 14, 2019

Published: May 17, 2019

\begin{abstract}
The genus Pachypodium are succulent shrubs and small trees found in Southern Africa. Climate change is identified as one the most important threat impacting plant and animal species in the South Africa today, and in this case study, we examined the Pachypodium bispinosum and Pachypodium succulentum species in South Africa, which are becoming more vulnerable due to climate change impacts as well as human threats. This study investigates the climate change impacts on the two Pachypodium species, as well as the biodiversity threats facing the Pachypodium species today, and provides evidence regarding the importance of the study to understanding the climate change impacts on the Pachypodium species by showing the underlying variables affecting the changes.
\end{abstract}

\section{Keywords}

Climate Change, Biodiversity Threats, Pachypodium Species, Pachypodium succulentum, Pachypodium bispinosum, Species Modelling

\section{Introduction}

The genus Pachypodium are succulent shrubs and small trees found in Southern Africa, and they are known for their attractive star-shaped flowers, swollen stems, and have spines (Variawa \& Pfab, 2018). The two species under investigation in the study are Pachypodium bispinosum and Pachypodium succulentum. These plants are spiny succulent shrubs that grow up to $60 \mathrm{~cm}$ in height, and have partially underground swollen tuberous stems. These swollen stems stores water to allow the Pachypodium species to withstand heat and periods of drought (Variawa \& Pfab, 2018) (Figure 1).

Climate change is identified as one the most important threat impacting plant and animal species in the South Africa today, and South Africa has the highest 


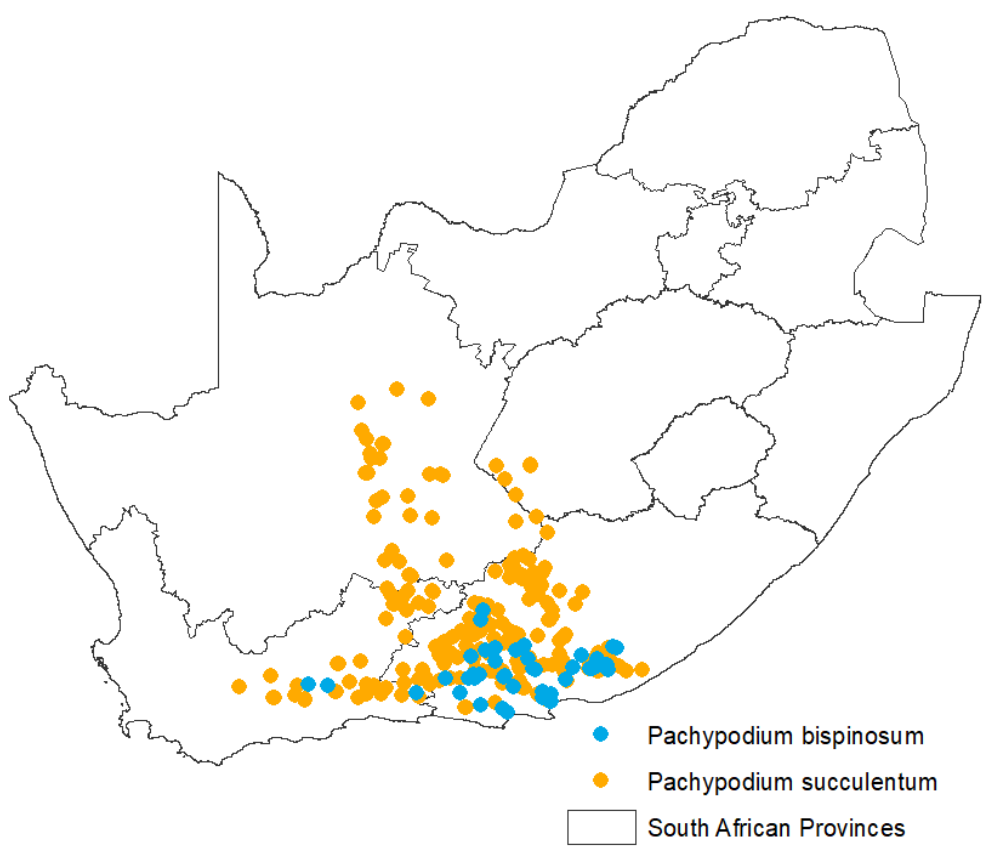

Figure 1. Pachypodium bispinosum and Pachypodium succulentum Sample Locations in South Africa.

concentration of threatened plant taxa in the world in terms of area and total numbers (DEA, 2011; Guo \& Arnolds, 2019). Climate change is a well researched scientific area, and climate change is mostly attributed to the burning of fossil fuels, over the past few decades, and which drastically increases the levels of carbon dioxide being released into the atmosphere (DEA, 2011; Flato et al., 2013). This results in an overall increase in average global temperatures and changes in the global rainfall patterns, and this could result in more extreme weather (DEA, 2011; Flato et al., 2013). As much of the succulent plants are resistant to local climate variabilities, but prolonged temperature and rainfall changes would have severe negative impacts on the Pachypodium species (Guo et al., 2017). In this study we examine mainly the climate change impacts upon the two Pachypodium species, and what factors impacts the species in the future.

However, one must mention that other biodiversity threats such as human impact as a result of human activities is also a major problem and a severe threat to the species. Both Pachypodium bispinosum and Pachypodium succulentum species are very popular and has good economic value in the horticultural trade, due to its attractive flowers, size, and large swollen stems. Local collectors dug up entire plants, and at times the entire population. Both species are under the risk for unsustainable use and overexploitation of wild populations (Variawa \& Pfab, 2018) (Figure 2).

\section{Climate Data and Methods}

In this study, we supplemented the with historical Acocks survey from SANBI database, and added in the SANBI survey 2010 data to insure a full coverage 

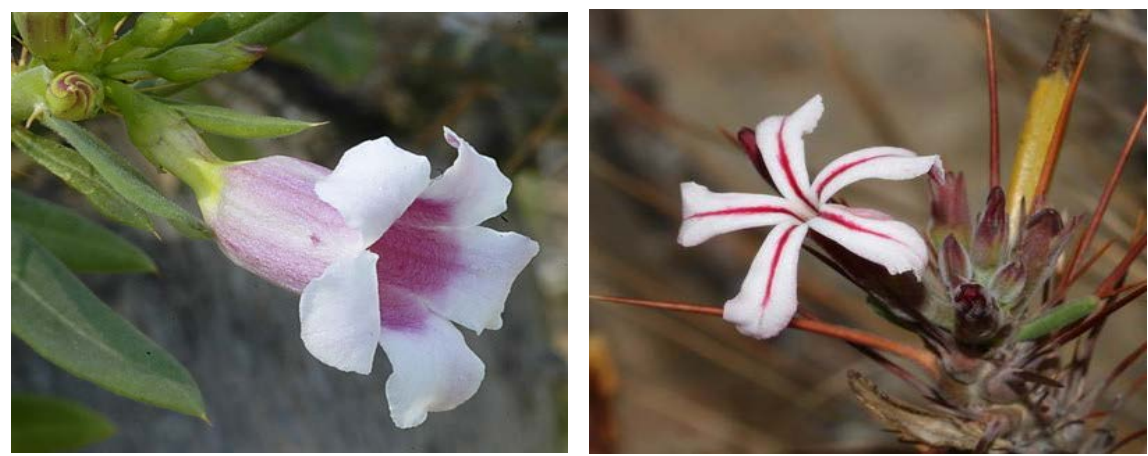

Figure 2. Pachypodium bispinosum (left-Photo: Brian du Preez) and Pachypodium succulentum (right-Photo: Mike Keeling) (iNaturalist, 2019).

when doing future modelling. We used the MPI-ESM-MR model from the Max Planck Institute for Meteorology was used in the study, it is a comprehensive Earth-System Model, and is a fairly conservative model and well suited for predictions of Southern African climate (Connolley \& Bracegirdle, 2007). For the future scenario, we selected the RCP8.5 as the future scenario, for future projected time period 2061-2080 (Hijmans et al. 2005). Representative Concentration Pathways (RCPs) are greenhouse gas concentration trajectories used by the Intergovernmental Panel on Climate Change for its fifth Assessment Report in 2014. The RCP8.5 assumes global annual emissions continues to rise throughout the 21 st century and is measured in $\mathrm{CO} 2$-equivalents, and this is a realistic future scenario based on the present human activity (Flato et al. 2013).

In order to examine the distribution and relationship between the Pachypodium species and the environmental and climatic variables, the distributions are modelled to show the climatic niche of the two Pachypodium species. A species distribution modelis used to estimate the relationship between the sample records (Booth et al., 2014), and the environmental and spatial characteristics of those sample sites (Franklin, 2009). The species distribution model used is MaxEnt, itapplies Bayesian methods to estimate the potential geographic distribution of species, by finding the probability distribution of maximum entropy(Phillips, Anderson, \& Schapire, 2006; Phillips, Dudík \& Schapire, 2004; Elith et al., 2011).

Gibbs sampling is a statistical algorithm used by Bayesian inference that is used in the MaxEnt program. The Gibbs family $\left\{q_{\lambda}(x), \lambda \in \mathrm{L}\right\}$, where

$$
q_{\lambda}(x)=\frac{1}{Z_{\lambda}(x)} \exp \left(\sum_{i=1}^{m} \lambda_{i} f_{i}(x)\right)
$$

and $\lambda_{i}=\left(\lambda_{1}, \lambda_{2}, \ldots, \lambda_{m}\right)$ is the weight vector, $\lambda_{i}$ is the weight parameters, and $\mathrm{L}$ is the $m$-dimensional space, with $f_{i}(x)$ representing species $i$ is probability distribution, and $Z_{\lambda}(x)$ is the normalized constant, and also each element $x$ is a pixel of the investigated area. The probabilities $f_{i}(x)$ represent the relative suitability of the environmental and climatic conditions in each pixel (Phillips, Anderson, \& Schapire, 2006; Phillips, Dudík, \& Schapire, 2004; Elith et al., 2011).

The climate variables used in the study are nineteen bioclimatic variables of 
BIOCLIM (Booth et al., 2014); and it is a bioclimatic prediction system which uses the bioclimatic parameters, derived from mean monthly climate estimates to estimate the energy and water balances at a given location (Fenner School, 2016; Nix, 1986). The nineteen climate variables are: Annual Mean Temperature, Mean Diurnal Range, Isothermality, Temperature Seasonality, Maximum Temperature of Warmest Month, Minimum Temperature of Coldest Month, Temperature Annual Range, Mean Temperature of Wettest Quarter, Mean Temperature of Driest Quarter, Mean Temperature of Warmest Quarter, Mean Temperature of Coldest Quarter, Annual Precipitation, Precipitation of Wettest Month, Precipitation of Driest Month, Precipitation Seasonality, Precipitation of Wettest Quarter, Precipitation of Driest Quarter, Precipitation of Warmest Quarter, and Precipitation of Coldest Quarter.

The environmental variables used in the study are altitude, aspect, lithology, rock type, landuse, land morphology, slope, and soiltype (Schulze, 2007, Macvicar et al., 1977; Soil Classification Working Group, 1991). These geological and environmental variables are carefully selected according to their observed effects on the Pachypodium species in the natural habitat.

\section{Projected Future Climate Change Impacts}

In modelling the future scenarios of the changes in Pachypodium species, change maps are produced of the Pachypodium succulentum and Pachypodium bispinosum. It is very surprising to see the amount of negative changes just based on climate changes, as geological environmental variables do not change.

In Figure 3, red colour shows the negative changes, green colour shows the positive changes, and the blue colour shows there is no change in the Pachypodium bispinosum distribution areas. It is clear from the map that the Pachypodium bispinosum distribution shows a major niche shrinkage and loss of habitat. This is highly unusual with so much negative loss in habitat, and shows the effect based on climate changes alone. While it does show an expansion of habitat in the edges, but it very little compared to the amount of loss of habitat, with very little remaining habitat left.

In Figure 4, red colour shows the negative changes, green colour shows the positive changes, and the blue colour shows there is no change in the Pachypodium succulentum distribution areas. It is clear from the map that the Pachypodium succulentum distribution shows a while showing a loss of habitat, it is much less severe than that of Pachypodium bispinosum. This shows the Pachypodium succulentum is less vulnerable to climate changes, perhaps in part due to its larger distribution area. However, this species still shows a large loss in habitat, but it also does show a positive change or expansion in the species.

\section{Discussion and Conclusion}

While we have examined the changes in Pachypodium bispinosum and Pachypodium succulentum species due to climate impacts, now we need to take a closer look at the variables that influence the changes in Pachypodium species. 


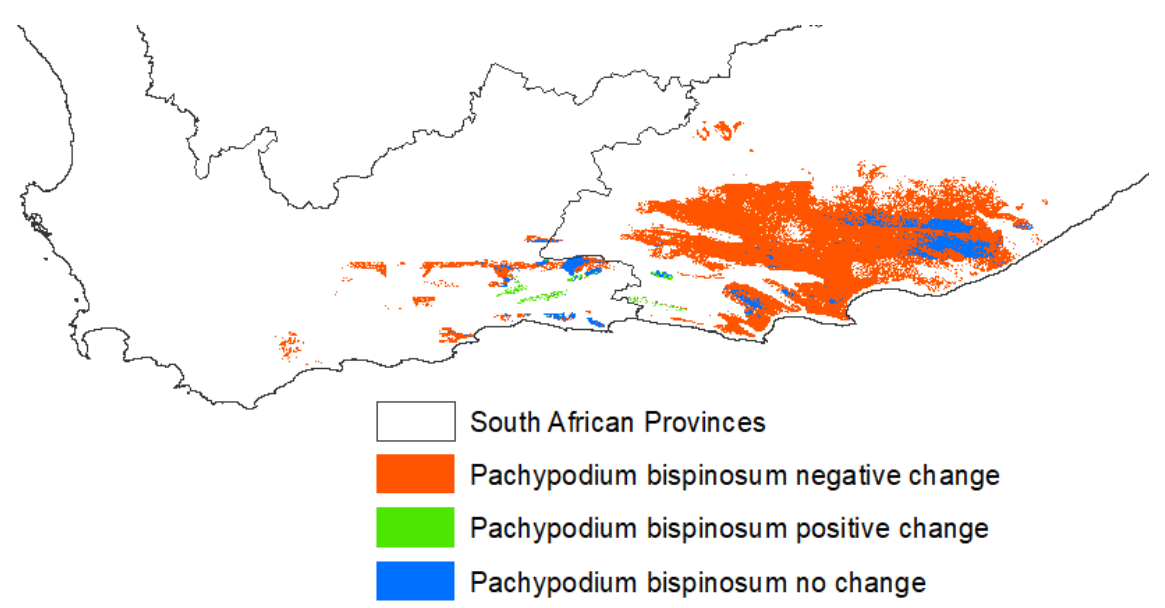

Figure 3. Projected future changes in Pachypodium bispinosum Distribution Areas.

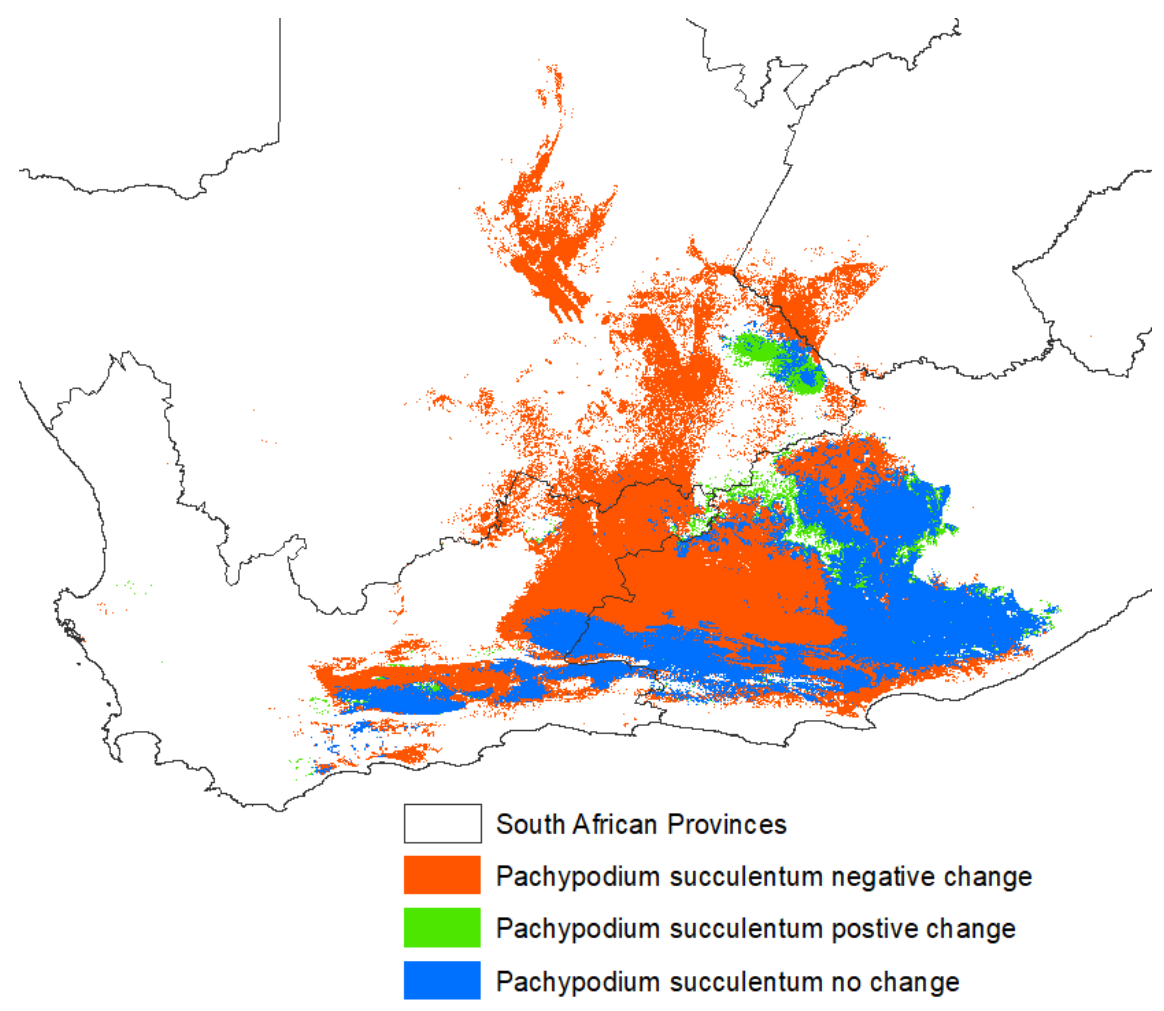

Figure 4. Projected future changes in Pachypodium succulentum Distribution Areas.

In Figure 5, it is clear that the fixed environmental variables contributes the most to the Pachypodium bispinosum niche area, though these soil and geological variables are unlikely to change in the next few decades. For the Pachypodium bispinosum, the soil type, land morphology, and altitude all have major contributions to the distribution of the species. The climate variables that does change in the future and makes a major impact on the species are: precipitation seasonality, and precipitation of the driest quarter, and precipitation of the warmest quarter. These climate variables obviously are not conductive toward 


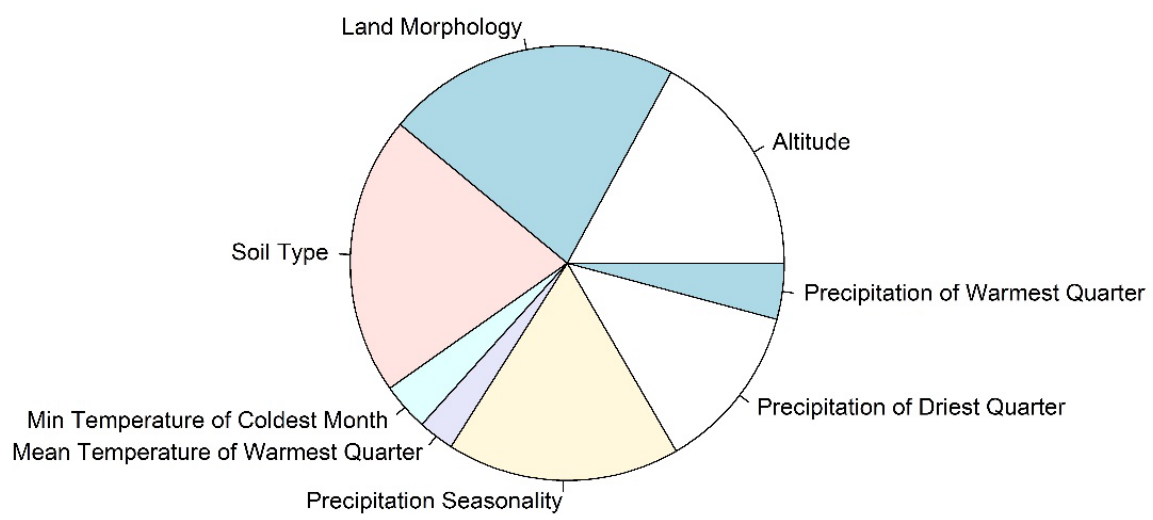

Figure 5. Pachypodium bispinosum environmental and climate variable contributions.

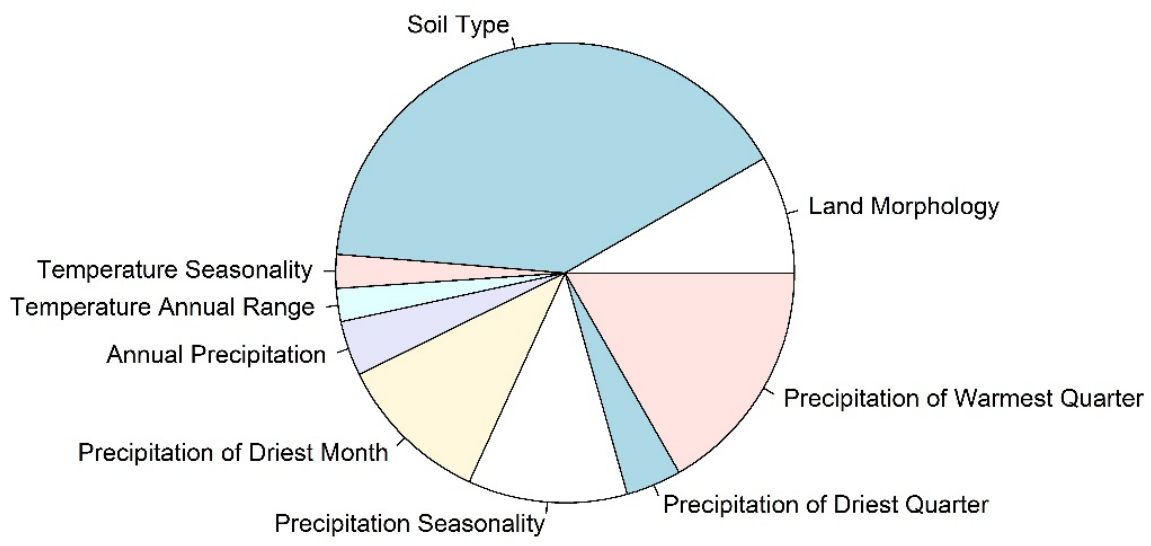

Figure 6. Pachypodium succulentum environmental and climate variable contributions.

the Pachypodium bispinosum in the future, and will impact the species negatively, as shown in Figure 3.

In Figure 6, again it is shown that the fixed environmental variables contributes the most to the Pachypodium succulentum niche area, but these soil and geological variables are unlikely to change in the next few decades. For the $\mathrm{Pa}$ chypodium succulentum, the soil type and land morphology variables both have major contributions to the distribution of the species. The climate variables that does change in the future and makes a major impact on the species are: precipitation of the warmest quarter, precipitation seasonality, and precipitation of the driest month. These climate variables impacts on the distribution of the Pachypodium succulentum in the future, and will impact the species both negatively and positively, as shown in Figure 4. It is of note that for both Pachypodium species it is not the temperature variables that impacts the distribution the most, but rather the precipitation variables are the most important changing impact factors.

This study demonstrates the importance of climate change as a major factor impacting the Pachypodium species, and given the human impacts on the species already currently, it is essential to develop policies and monitoring systems for the Pachypodium species (Variawa \& Pfab, 2018). At this stage, one cannot 
claim extinction risks as yet, because the climate induced changes are also sensitive to the underlying habitat model, and needs to consider other factors such as life history, recruitment response to fire, dispersal dynamics... and combined with the human impacts and economic value, it can be quite complex to try to predict the species vulnerability (Fordham et al., 2012).

\section{Acknowledgements}

Sincere thanks to the South African National Biodiversity Institute (SANBI) for their data and support of the project; to the CGIAR Research Program on Climate Change, Agriculture and Food Security (CCAFS) and WorldClim for the climate data; to the Agricultural Research Council (ARC)-Institute for Soil, Climate and Water, and the AGIS Development Centre for the soil data; and to the South African Atlas of Climatology and Agrohydrology from the Water Research Commission for the environmental data.This research is supported financially by the National Research Foundation (NRF) of South Africa, NRF Funding Reference: IFR150206113775 Grant number: 96163.

\section{Conflicts of Interest}

The authors declare no conflicts of interest regarding the publication of this paper.

\section{References}

Booth, T. H., Nix, H. A., Busby, J. R., \& Hutchinson, M. F. (2014). BIOCLIM: The First Species Distribution Modelling Package, Its Early Applications and Relevance to Most Current MAXENT Studies. Diversity and Distributions, Biodiversity Review, 20, 1-9. https://doi.org/10.1111/ddi.12144

Connolley, W. M., \& Bracegirdle, T. J. (2007). An Antarctic Assessment of IPCC AR4 Coupled Models. Geophysical Research Letters, 34, L22505.

https://doi.org/10.1029/2007GL031648

Department of Environmental Affairs (DEA) (2011). State of the Environment. Threatened Species. https://www.environment.gov.za/

Elith, J., Phillips, S. J., Hastie, T., Dudík, M., Chee, Y. E.,\& Yates, C. J. (2011). A Statistical Explanation of MaxEnt for Ecologists. Diversity and Distributions, 17, 43-57. https://doi.org/10.1111/j.1472-4642.2010.00725.x

Fenner School (2016). ANUCLIM.

http://fennerschool.anu.edu.au/research/products/anuclim-vrsn-61

Flato, G., Marotzke, J., Abiodun, B., Braconnot, P., Chou, S. C., Collins, W., Cox, P., Driouech, F., Emori, S., Eyring, V., Forest, C., Gleckler, P., Guilyardi, E., Jakob, C., Kattsov, V., Reason, C., \& Rummukainen, M. (2013). Evaluation of Climate Models. In T. F. Stocker, D. Qin, G. K. Plattner, M. Tignor, S. K. Allen, J. Boschung, A. Nauels, Y. Xia, V. Bex, \& P. M. Midgley (Eds.), Climate Change 2013: The Physical Science Basis, Contribution of Working Group I to the Fifth Assessment Report of the Intergovernmental Panel on Climate Change. Cambridge, UK and New York, NY, USA: Cambridge University Press.

Fordham, D. A., Akçakaya, H. R., Araújo, M. B., Elith, J., Keith, D. A., Pearson, R., Auld, T. D., Mellin, C., Morgan, J. W., Regan, T. J., Tozer, M., Watts, M. J., White, M., Win- 
tle, B. A., Yates, C., \& Brook, B. W. (2012). Plant Extinction Risk under Climate Change: Are Forecast Range Shifts Alone a Good Indicator of Species Vulnerability to Global Warming? Global Change Biology, 18, 1357-1371.

https://doi.org/10.1111/j.1365-2486.2011.02614.x

Franklin, J. (2009). Mapping Species Distributions: Spatial Inference and Prediction. Cambridge, UK: Cambridge University Press. https://doi.org/10.1017/CBO9780511810602

Guo, D., \& Arnolds, J. L. (2019). Chapter 9: Biodiversity of South Africa. In T. Pullaiah (Ed.), Global Biodiversity, Volume 3: Selected Countries in Africa. Apple Academic Express. Milton Park, Abingdon-on-Thames: CRC Taylor \& Francis Group.

Guo, D., Young, A. J., Desmet, P. G., \& Midgley, G. F. (2017). Climate Change Impacts on Dwarf Succulents in Namibia as a Result of Changes in Fog and Relative Humidity. Journal of Water Resource and Hydraulic Engineering (JWRHE), 6, 57-63. https://doi.org/10.5963/JWRHE0603004

Hijmans, R. J., Cameron, S. E., Parra, J. L., Jones, P. G., \& Jarvis, A. (2005). Very High Resolution Interpolated Climate Surfaces for Global Land Areas. International Journal of Climatology, 25, 1965-1978. https://doi.org/10.1002/joc.1276

iNaturalist (2019). The iNaturalist Network. Powered by iNaturalist Open Source Software. https://www.inaturalist.org/

Macvicar, C. N., Loxton, R. F., Lambrechts, J. N. N., Le Roux, J., De Villiers, J, M., Verster, E., Merryweather, F. R., Van Rooyen, T, H., Harmse, H. J., \& Von, M. (1977). Soil Classification. A Binomial System for South Africa. Pretoria, South Africa: Library Holding ZA 1977.02 Report.

Nix, H. (1986). Abiogeographic Analysis of Australian Elapid Snakes. In R. Longmore (Eds.), Snakes: Atlas of Elapid Snakes of Australia (pp. 4-10). Canberra: Bureau of Flora and Fauna.

Phillips, S. J., Anderson, R. P., \& Schapire, R. E. (2006). Maximum Entropy Modeling of Species Geographic Distributions. Ecological Modelling, 190, 231-259. https://doi.org/10.1016/j.ecolmodel.2005.03.026

Phillips, S. J., Dudík, M., \& Schapire, R. E. (2004). A Maximum Entropy Approach to Species Distribution Modeling. Proceedings of the Twenty-First International Conference on Machine Learning, Banff, Alberta, 4-8 July 2004, 655-662. https://doi.org/10.1145/1015330.1015412

Schulze, R. E. (Eds.) (2007). South African Atlas of Climatology and Agrohydrology. Pretoria, RSA: Water Research Commission, WRC Report 1489/1/06, Section 1.1.

Soil Classification Working Group (1991). Soil Classification. A Taxonomic System for South Africa. Pretoria, South Africa: Department of Agricultural Development, Library holding ZA 1991.01 Report.

Variawa, T., \& Pfab, M. F. (2018). The Field Status of Three South African Pachypodium Species: Implications for Sustainable Trade. Draft Report Compiled for the Scientific Authority of South Africa. 